\title{
IMPLEMENTASI ECONOMIC ORDER QUANTITY (EOQ) UNTUK MENGHITUNG PERSEDIAN BAHAN BAKU TAHU
}

\author{
Purnamasari'), Muhammad Sarjan ${ }^{2)}$, Muhammad Assidiq ${ }^{3)}$ \\ 1,2,3 Program Studi Sistem Informasi \\ UNIVERSITAS AL ASYARIAH MANDAR \\ Jl. Budi Utomo No. 2 Polewali Mandar, Sulawesi Barat
}

\begin{abstract}
ABSTRAK
Proses manajemen persediaan bahan baku Tahu pada industri rumahan sangat krusial jika kedelai terlalu lama disimpan digudang maka kualitas kedelai pun akan menurun atau bahkan rusak sehingga hal ini menimbulkan kerugian bagi pabrik. Persediaan dapat dikendalikan dengan Model Economic Order Quantity (EOQ) metode dapat menghasilkan perhitungan jumlah pesanan ekonomis dengan biaya seminimal mungkin. Penelitian ini bertujuang untuk mengetahui jumlah persediaan bahan baku yang tepat. Hasil penelitian ini dibangun menggunakan bahasa pemrograman Visual Studio 2008 dengan Microsoft Acces untuk membangun databasenya dan data report yang merupakan paket dari Visual Basic itu sendiri untuk membuat laporannya.
\end{abstract}

Kata Kunci : Sistem Informasi Persediaan, EOQ, Bahan Baku Tahu

\begin{abstract}
The management process of tofu raw material inventory in the home industry is very crucial if soybeans are stored too long in the warehouse, so the quality of soybeans will decrease or even be damaged so that this causes losses to the factory. Inventory can be controlled with a Model Economic Order Quantity (EOQ) method that can produce calculations of economical order quantities at the minimum cost. This research aims to find out the right amount of raw material inventory. The results of this study were built using VisualBasic 6.0 programming language with Microsoft Access to build the database and data report which is a package from Visual Basic itself to make the report.
\end{abstract}

Keywords : Inventory Information System, EOQ, Tofu Raw Materials 


\section{PENDAHULUAN}

Pabrik tahu pak Damono merupakan sebuah industri rumahan yang siklus kegiatannya membeli, mengolah dan memasarkan tahu. Pabrik tahu ini didirikan sejak tahun 2000. Dulunya pabrik ini hanyalah pabrik kecil, hingga kini berkembang menjadi pabrik yang sudah banyak dikenal di daerah Malunda dan menjadi penyuplai tahu ke beberapa pasar yang ada di kabupaten majene.

Bahan baku utama dalam pembuatan tahu yaitu kedelai. Pemesanan kedelai dilakukan perbulan, satu kali pemesanan sekitar 7 ton kedelai. Pihak pabrik melakukan pemesanan kedelai pada satu pemasok. Dalam satu hari diproduksi sebanyak 12.000 tahu,dengan pemakaian sebanyak 3 kuintal kedelai. Bagian pembelian akan melakukan kembali pemesanan bahan baku kedelai ketika persediaan yang ada di gudang sudah sedikit. Hal ini menimbulkan biaya pemesanan untuk tiap kali transaksi pemesanan kedelai. Terkadang jumlah pemesanan kedelai sebanyak 7 ton itu tidak habis dalam satu bulan. Jumlah bahan baku yang tersimpan di gudang tentunya menimbulkan biaya penyimpanan. Jika kedelai terlau lama disimpan di gudang maka kualitas kedelai pun akan menurun atau bahkan rusak sehingga harus dibuang dan itu akan merugikan pihak pabrik. Biaya persediaan menjadi tidak optimal ketika kuantitas dan frekuensi pemesanan tidak dapat diprediksi dengan baik. Ditambah dengan biaya penyimpanan yang timbul ketika kuantitas pembelian bahan baku berlebih.

Persoalan Pak Damono dapat diminimalisir agar persedian sesuai dengan kebutuhan dan bahan baku tidak terlalu lama digudang, metode Economic order quantity (EOQ) dapat digunakan untuk mengelola persedian (N. Tungalag, 2017), dapat memprediksi jumlah pesanan secara ekonomis (Kumar 2016); (Aju Mathew, 2013). Penelitian akan menggunakan EOQ untuk menghitung jumlah persedian yang harus terpenuhi pada industri rumahan yang mengelola usaha tahu.

\section{LANDASAN TEORI dan METODE}

\subsection{SistemPengelolaan Inventori dan EOQ Motode}

Kemampuan suatu perusahaan dalam mengatur dan mengelola setiap kebutuhan barang baik barang mentah, barang setengah jadi, dan barang jadi agar selalu tersedia baik dalam kondisi pasar yang stabil dan berfluktuasi merupakan manajemen sistem pengelolaan perssedian dalam sebuah perusahaan (Reza, 2016). Perusahaan dapat menerapkan konsep manajemen persediaan (inventory management) untuk menekan biaya persediaan bahan baku seoptimal mungkin

Pengelolaan Inventori membutuhkan sebuah metode perhitungan dan Model Economic Order Quantity (EOQ) klasik mungkin adalah model keputusan inventaris yang paling dikenal dan paling mendasar, EOQ mampu memberi informasi mengenai jumlah minimal dari biaya penyimpanan persedian dan biaya pemesanan (Aro-Gordon and Gupte, 2016). Tujuan model tersebut adalah untuk menentukan jumlah ekonomis setiap kali ordering (EOQ). Economic Order Quantity (EOQ) telah terkenal formula yang menghitung kuantitas pesanan ekonomi optimal (Jose L. Gonzalez and Daniel González, 2010). Berikut adalah grafik proses pada EOQ.

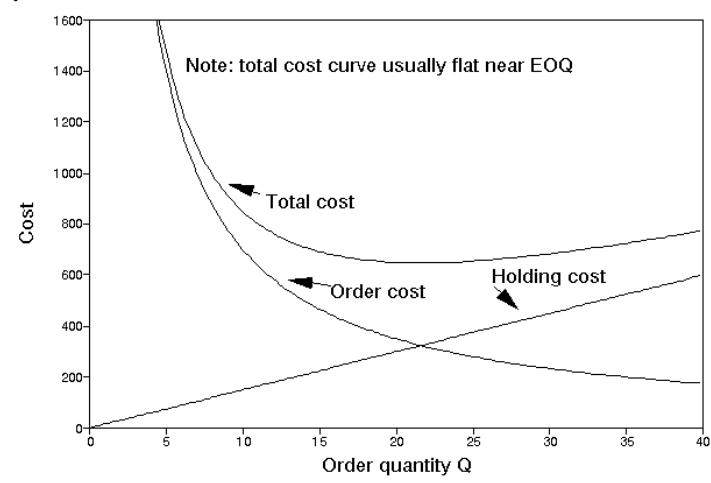

Gambar 1. Grafik Proses EOQ (Cargal, 2009)

Gambar 1 menjelaskan Kuantitas Pesanan Ekonomi sebagai, "Menentukan pesanan kuantitas "Q", yang menyeimbangkan biaya pesanan " $\mathrm{C}$ " dan biaya penyimpanan " $\mathrm{H}$ ", untuk meminimalkan total biaya. Implementasi EOQ menggunakan formula sebagai berikut (Cargal, 2009):

$$
Q^{*}=\sqrt{\frac{2 D S}{H}}
$$

Keterangan:

$\mathrm{Q}=$ jumlah pesanan EOQ. Ini adalah variabel yang ingin kami optimalkan. Yang lainnya variabel adalah jumlah tetap.

$\mathrm{D}=$ permintaan tahunan produk dalam jumlah per unit waktu. Ini juga bisa diketahui sebagai tingkat.

$\mathrm{S}=$ biaya pesanan produk. Ini adalah biaya tetap yang dikenakan untuk membuat pesanan apa pun dan apa adanya independen dari Q.

$\mathrm{C}=$ Biaya satuan .

$\mathrm{H}=$ Holding cost per unit sebagai sebagian kecil dari biaya produk.

\subsection{Implementasi Program Visual Studio 2008}

Visual Studio memungkinkan perancangan antarmuka pengguna dapat dengan mudah dibuat dan didukung oleh NET Compact Framework untuk mengontrol tombol, kotak teks, dan bentul lainnya (. Visual Studio sebagai sebuah bahasa pemrograman juga memiliki beberapa cara penulisan serta aturan yang harus diketahui untuk membuat aplikasi yang baik, diantaranya :

a) Cara penulisan Event Procedure 
Procedure Event adalah kode-kode program yang dijalankan apabila event dari suatu objek (kontrol) dipicu oleh user. Procedure Event dimulai dengan kalimat Private Sub dan diakhiri dengan kalimat End Sub. Blok ini membentuk awal dan akhir dari suatu procedure event.

\section{b) Cara Penulisan Event}

Visual Studio sudah menyediakan event-event pada suatu daftar yang hanya memilih yang mana yang dibutuhkan. Klik pada kotak daftar nama event disebelah kanan atas jendela kode untuk menampilkan daftar event-event yang bisa digunakan. Setiap kali memilih salah satu event pada daftar tersebut, secara otomatis akan dibuat sebuah kerangka program untuk event tersebut beserta kontrolnya yang bersangkutan.

\section{HASIL DAN PEMBAHASAN}

Sebuah program aplikasi digunakan untuk menghitung jumlah jumlah pesanan EOQ. Ini adalah variabel yang ingin kami optimalkan. Yang lainnya variabel adalah jumlah tetap. Tampilan awal aplikasi $\mathrm{d}$ apat dilihat pada gambar 1

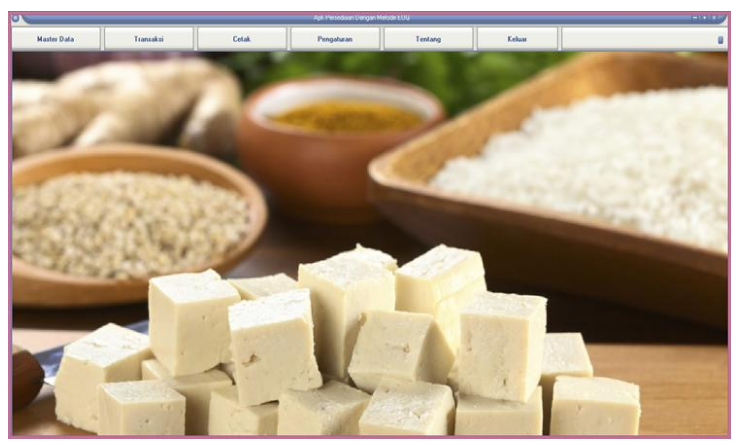

Gambar 1 Tampilan awal aplikasi

Contoh Kasus: Industri rumahan Pak Damono yang menjual tahu ke seorang pengecer, Pihak pengecer bermaksud mengurangi biaya persediaannya dengan menentukan jumlah tahu yang optimum untuk setiap pemesanan. Pada kasus ini diketahui Demand tahunan adalah 1,000 ton setup atau ordering cost adalah \$10 setiap order; dan holding cost per unit per tahun adalah $\$ 0.50$. Dengan menggunakan angka ini, jumlah ton yang optimum setiap kali pemesanan sebagai berikut:

Diketahui :

Demand (D)

$: 1.000$

Ordering Cost (S)

$: \$ 10$

holding Cost $(\mathrm{H})$

$: \$ 0.50$

Ditanyakan

Penyelesaian:

$$
\begin{aligned}
& Q^{*}=\sqrt{\frac{2 D S}{H}} \\
& \begin{array}{l}
\text { Co } \\
h t t_{i}
\end{array} \quad Q^{*}=\sqrt{\frac{2(1,000)(10)}{0.50}}=\sqrt{40,000}=200
\end{aligned}
$$

Jumlah order yang diharapkan sepanjang tahun (N) dan waktu antar ordering yang diharapkan (T) juga dapat ditentukan,sebagai berikut :

Jumlah pesanan $=N=\frac{\text { Demand }}{\text { Kuantitaspemesanan }}=\frac{D}{Q^{*}}$

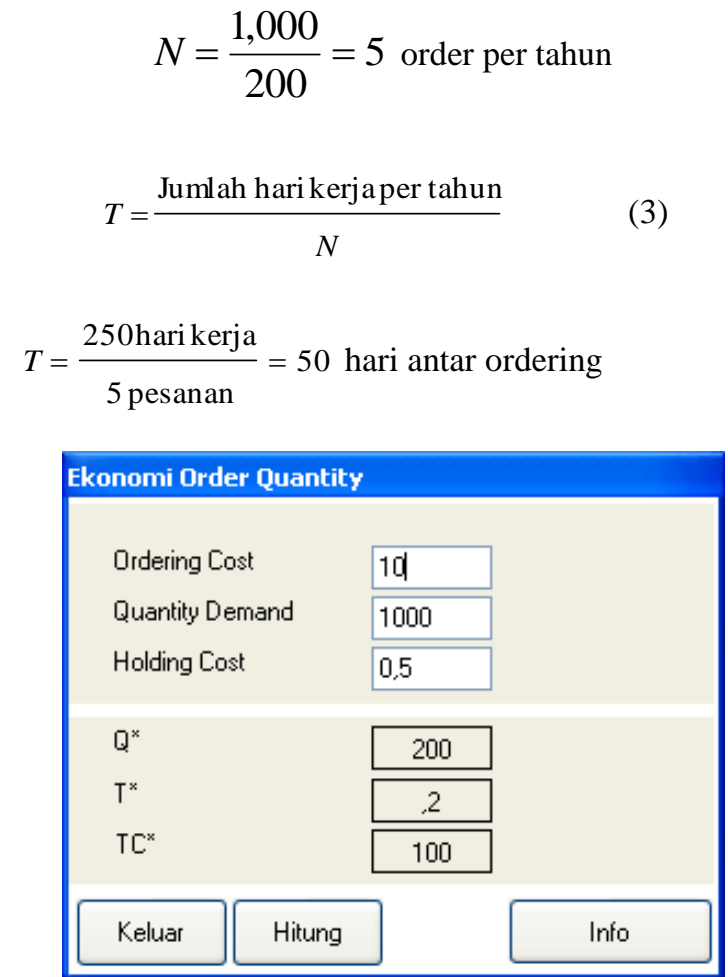

Gambar 2. Proses Hitung EOQ

\section{KESIMPULAN}

Berdasarkan hasil penelitian dan pembahasan, maka dapat ditarik kesimpulkan bahwa aplikasi ini dapat membantu user untuk mengelola pembelian bahan baku produksi berdasarkan hasil EOQ serta membantu memenuhi target penjualan.

\section{Ucapan Terima Kasih}

Ucapan terima kasih kepada Rektor dan Dekan serta Kepala Laboratorium riset Fakultas Ilmu Komputer Universitas Al Asyariah Mandar.

\section{Daftar Pustaka}

Aju Mathew,Prof.E.M.Somasekaran Nair**,Asst Prof. Jenson Joseph E, 2013, International Journal of Scientific and Research Publications, Volume 3, Issue 10, Mechanical Engineering Department, SCMS School of Engineering and Technology,Karukutty, Kerala ISSN 2250-3153

Cargal, James M. "The EOQ Inventory Formula." Http://www.cargalmathbooks.com. Web. 15 Nov. 2009.http://www.cargalmathbooks.com/The\%20EO Q\%20Formula.pdf>.

Devadrita Dey Sarkar, 2015, Visual Studio Professional: A Benchmark in Bioinformatics, International 
Journal of Computer Science And Technology, IJCST Vol. 6, Iss ue 2, April - June,ISSN : 09768491 (Online) | ISSN : 2229-4333 (Print) www. i j c s t. c o m

Jose L. Gonzalez and Daniel González, 2010, Analysis of an Economic Order Quantity and Reorder Point Inventory Control Model for Company XYZ, Science in Industrial Engineering, California Polytechnic State University, San Luis Obispo

Rakesh Kumar, 2016, Economic Order Quantity (EOQ) Model, Global Journal of Finance and Economic Management. ISSN 2249-3158 Volume 5, Number 1 (1-5), Research India Publications http://www.ripublication.com

S. ARO-GORDON dan Jaideep GUPTE, 2016, Overview Of The Classic Economic Order Quantity Approach To Inventory Management, The Business Age, ISSN: 2455-9423 